Dalton : Jurnal Pendidikan Kimia dan Ilmu Kimia, Volume 2 Nomor 1, Mei 2019

\title{
KOMPARASI PEMBELAJARAN KIMIA MENGGUNAKAN METODE TEAMS-GAMES TOURNAMENT DAN TEAM-ASSISTED INDIVIDUALIZATION TERHADAP HASIL BELAJAR PADA MATERI AJAR TATA NAMA SENYAWA KELAS X SMA NEGERI 12 BANJARMASIN
}

\section{Comparison of Chemistry Learning Using Teams-Games Tournament and Teams-Assisted Individualization Method Towards Learning Outcomes on Compounds Nomenclature Topic at Class X SMA Negeri 12 Banjarmasin}

Siti Mahmudah, Fitrah Yuridka, Mohan Taufiq Mashuri

Program Studi Pendidikan Kimia Fakultas Keguruan dan Ilmu Pendidikan Universitas Islam Kalimantan (Uniska) Muhammad Arsyad Al Banjari, Banjarmasin *e-mail: Arifadaapanya@gmail.com

\begin{abstract}
Abstrak. Penelitian ini dilaksanakan di SMA Negeri 12 Banjarmasin dengan tujuan untuk mengetahui ada tidaknya perbedaan hasil belajar menggunakan metode TGT (Teams Games Tournament) dan metode TAI (Team Assisted Individualization) pada materi tata nama senyawa. Penelitian ini merupakan penelitian eksperimen semu (quasi-experimental research). Populasi pada penelitian ini adalah seluruh siswa kelas X MIA di SMA Negeri 12 Banjarmasin yang terdiri dari 3 kelas yaitu kelas X MIA 1, X MIA 2, dan X MIA 3. Sampel dalam penelitian ini yaitu kelas X MIA 2 sebagai kelas eksperimen 1 dan kelas X MIA 3 sebagai kelas eksperimen 2. Teknik pengumpulan data yang digunakan dalam penelitian ini adalah tes. Dari hasil analisis data dengan uji-t diperoleh nilai thitung $(2,999)>$ tabel $(1,683)$, yang berarti terdapat perbedaan hasil belajar menggunakan metode TGT dan metode TAI pada materi ajar tata nama senyawa, dimana rata-rata nilai hasil belajar kelas yang menggunakan metode TAI sebesar 79,62 lebih tinggi daripada kelas metode TGT sebesar 72,45. Untuk meningkatkan hasil belajar kimia siswa, pembelajaran dengan menggunakan metode TGT dan TAI dapat menjadi bahan pertimbangan oleh guru-guru kimia sebagai variasi dalam melaksanakan pembelajaran kimia.
\end{abstract}

Kata Kunci : Hasil belajar, tata nama senyawa, team assisted individualization, teams games tournaments

Abstract. This research was done in SMA Negeri 12 Banjarmasin by aiming to know if there was a difference between learning outcomes by using TGT (TeamsGames Tournament) and TAI (Team-Assisted Individualization) method on compounds nomenclature topic. It was a quasi-experimental research. The population in this study were all students of class X MIA in SMA Negeri 12 Banjarmasin consisting of 3 classes, namely class X MIA 1, X MIA 2, and X MIA 3. The samples in this study were class X MIA 2 as the experimental class 1 and class X MIA 3 as the experimental class 2. The data technique used in this study was a test. From the results of data analysis with t-test obtained $t_{\text {count }}(2.999)>$ $t_{\text {table }}(1.683)$, which meant that there was difference in learning outcomes using the TGT and TAI methods on compound nomenclature, where the average learning 
Dalton : Jurnal Pendidikan Kimia dan Ilmu Kimia, Volume 2 Nomor 1, Mei 2019

outcomes of the TAI class was 79.62 which was higher than the TGT class, 72.45 . In order to improve student learning outcomes, learning using TGT and TAI methods can be taken into consideration by chemistry teachers as variations in learning.

Keywords: Compound nomenclature, learning outcomes, team assisted individualization, teams games tournaments

\section{PENDAHULUAN}

Lulusan yang bermutu merupakan target dari hampir semua lembaga pendidikan agar lulusannya mampu menghadapi tantangan yang ada dan bertahan dalam dunia kerja (Arjanggi \& Suprihatin, 2010). Pendidikan akan menghasilkan keluaran (output dan outcome) yang bermutu bila proses pembelajarannya bermutu. Pembelajaran dapat dikatakan bermutu jika semua unsur dalam pembelajaran dapat berjalan dengan sebaikbaiknya (Suhadi, Mujahidin, Bahrudin, \& Tafsir, 2014). Proses pembelajaran yang bermutu dapat dilaksanakan dalam berbagai pendekatan. Pendekatan pembelajaran yang diyakini efektif dan efisien saat ini adalah pendekatan pembelajaran aktif dimana anak didik dapat berinteraksi dengan sesamanya ataupun pengajar sehingga mereka dapat berperan aktif dalam pembelajaran (Nurdyansyah \& Toyiba, 2018).

Pembelajaran aktif (active learning) dimaksudkan untuk mengoptimalkan penggunaan semua potensi yang dimiliki oleh anak didik, sehingga semua anak didik dapat mencapai hasil belajar yang memuaskan sesuai dengan karakteristik pribadi yang mereka miliki (Rosida \& Suprihatin, 2011). Model active learning dimaksudkan untuk mengkondisikan agar siswa selalu melakukan pengalaman belajar yang bermakna dan senantiasa berpikir tentang apa yang dapat dilakukannya selama pembelajaran (Warsono \& Hariyanto, 2012).

Banyak cara bagi seorang guru untuk menyampaikan materi pelajaran kimia yang akan membuat siswa aktif, diantaranya adalah dengan menggunakan pendekatan atau metode pembelajaran yang tepat. Metode pembelajaran yang dapat mengaktifkan siswa antara lain TGT (Teams Games Tournaments) dan TAI (Team Assisted Individualization). TGT (Teams Games Tournaments) adalah salah satu metode dalam pembelajaran model kooperatif yang mudah diterapkan, melibatkan aktivitas seluruh siswa tanpa harus ada perbedaan status, melibatkan siswa sebagai tutor sebaya dan mengandung unsur permainan serta penguatan (reinforcement) (Sarwendah, Martini, \& Utami, 2013). TAI (Team Assisted Individualization) adalah suatu metode dalam pembelajaran model kooperatif dimana dalam suatu kelompok siswa harus berperan secara aktif dalam memecahkan masalah berdasarkan pengalamannya (Hariyati, Mardiyana, \& Usodo, 2013).

Dari hasil wawancara dengan beberapa siswa SMA Negeri 12 Banjarmasin, dapat diketahui bahwa sebagian besar siswa menganggap bahwa mata pelajaran kimia adalah mata pelajaran yang sulit dipahami dan membosankan karena pada umumnya berisi materi yang sifatnya hafalan dan hitung-hitungan yang rumit sehingga membutuhkan daya ingat yang kuat, kreatifitas dan daya imajinasi tinggi yang harus dimiliki oleh siswa. Akibatnya banyak siswa yang kurang atau bahkan tidak tertarik dalam memahami dan menguasai konsep-konsep dasar pada materi kimia. Dalam kegiatan belajar mengajar pelajaran kimia kelas X di SMA Negeri 12 Banjarmasin, khususnya pada materi tata nama senyawa guru masih menggunakan metode konvensional sehingga 
siswa kurang dilibatkan secara aktif, sehingga hal tersebut menyebabkan prestasi belajar siswa menjadi kurang maksimal. Maka dari itu, perlu dilakukan variasi metode pembelajaran yang dapat meningkatkan keaktifan siswa sehingga siswa tidak merasa jenuh atau bosan dalam kegiatan belajarnya. Dalam penelitian ini, metode yang diterapkan adalah TGT dan TAI yang ditujukan untuk melihat adanya perbedaan prestasi belajar siswa pada materi tata nama senyawa.

Penelitian terdahulu yang mendukung penelitian ini adalah penelitian yang dilakukan oleh Sarwendah, Martini, dan Utami (2013) yang menyatakan bahwa terdapat perbedaan prestasi belajar aspek kognitif siswa antara penggunaan metode Teams Games Tournament (TGT) dan metode Team Assisted Individualization (TAI) pada materi pokok sistem koloid. Hal ini terlihat dari rata-rata selisih nilai posttest sebesar 27,5 untuk kelas eksperimen I dan 34,5 untuk kelas eksperimen II, dengan hasil uji t-dua pihak diperoleh $t_{\text {hitung }}<\mathrm{t}_{\text {tabel }}$ yaitu $-2,558<-1,991$. Sehingga berdasarkan masalah dan hasil penelitian tersebut, maka penulis tertarik untuk melakukan penelitian yang berjudul "Komparasi Pembelajaran Kimia Menggunakan Metode TGT (Teams Games Tournament) dan TAI (Team Assisted Individualization) Terhadap Hasil Belajar pada Materi Ajar Tata Nama Senyawa Kelas X SMA Negeri 12 Banjarmasin".

\section{METODE PENELITIAN}

Jenis penelitian ini adalah eksperimen semu (quasi eksperimental research) dengan desain penelitian yang berbentuk Randomized Pretest-Posttest Comparison Group. Penelitian dilaksanakan di SMA Negeri 12 Banjarmasin mulai 3 sampai dengan 20 April 2018. Populasi dari penelitian ini adalah seluruh kelas X MIA sedangkan sampel penelitian yaitu kelas X MIA 2 sebagai kelas eksperimen 1 dan kelas X MIA 3 sebagai kelas eksperimen 3 dengan menggunakan teknik cluster sampling (Margono, 2014). Instrumen yang digunakan dalam penelitian ini yaitu silabus, rencana pelaksanaan pembelajaran (RPP), dan soal tes. Sebelum instrumen-instrumen tersebut dapat digunakan dalam penelitian maka perlu diuji kelayakannya. Untuk silabus dan RPP dengan meminta judgement pada dosen atau orang yang dianggap ahli sedangkan untuk soal tes menggunakan rumus perhitungan uji validitas, uji reliabilitas, uji tingak kesukaran, dan uji daya pembeda. Validasi dilakukan di kelas XI MIA 1. Uji validitas dihitung menggunakan rumus korelasi product moment yang dikemukakan oleh Pearson (Sujarweni \& Endrayanto, 2012), uji reliabilitas menggunakan rumus cronbach alpha (Arikunto, 2006), uji tingkat kesukaran menggunanakan rumus indeks kesukaran dan uji daya pembeda menggunakan rumus daya pembeda menurut Arikunto (2006). Kemudian setelah data penelitian diperoleh, data perlu melalui uji persyaratan yaitu uji normalitas dan uji homogenitas. Uji normalitas menggunakan rumus Kolmogorov-Smirnov (Sugiyono, 2013), sedangkan uji homogenitas untuk dua kelompok data menggunakan rumus uji F (Irianto, 2009). Setelah melalui uji persyaratan, maka diuji hipotesis. Jika data normal dan homogen maka menggunakan uji beda dua rata-rata populasi (independent sample t-test).

\section{HASIL DAN PEMBAHASAN}

Hasil analisis uji validitas soal tes menggunakan rumus korelasi product moment dari 40 soal pilihan ganda dan 10 soal uraian, diperoleh 15 soal pilihan ganda dan 8 soal

uraian valid. Setelah dinyatakan valid, soal tes diuji reliabilitasnya menggunakan rumus 
cronbach alpha, nilai cronbach alpha untuk soal pilihan ganda sebesar 0.92 dan untuk soal uraian sebesar 0.846 , dimana kedua nilai tersebut memiliki tingkat reliabilitas instrumen yang sangat tinggi; dengan kata lain, soal tes dapat dipercaya untuk digunakan sebagai alat pengumpul data. Setelah dinyatakan valid dan reliabel, butir soal tersebut kemudian diuji tingkat kesukarannya. Dari 15 soal pilihan ganda terdapat 1 soal mudah, 12 soal sedang, dan 2 soal sukar. Sedangkan dari 8 soal uraian terdapat 1 soal mudah, 4 soal sedang, dan 3 soal sukar. Langkah selanjutnya yaitu diuji daya bedanya. Dari 15 soal pilihan ganda, terdapat 4 soal berkriteria cukup, 7 soal berkriteria baik, dan 4 soal berkriteria sangat baik. Sedangkan dari 8 soal uraian, terdapat 2 soal berkriteria cukup dan 6 soal berkriteria baik. Dengan demikian soal-soal tes yang digunakan telah memenuhi syarat-syarat validitas, reliabilitas, taraf kesukaran, dan daya pembeda. Kemudian peneliti menggunakan ke-lima belas soal pilihan ganda dan lima dari delapan soal uraian sebagai instrumen penelitian soal tes.

Soal tes dibagikan pada siswa sebelum diberi perlakuan (pretest) dan sesudah diberi perlakuan (posttest) dimana kelas eksperimen 1 menggunakan metode TGT sedangkan kelas eksperimen 2 menggunakan metode TAI. Setelah didapatkan data pretest dan posttest maka data diuji normalitas dan homogenitasnya. Berdasarkan analisa data yang telah dilakukan, diperoleh hasil bahwa data berdistribusi normal dan homogen. Selanjutnya dilakukan uji-t untuk menguji hipotesis. Hasil uji-t yang dilakukan terhadap hasil belajar siswa adalah sebesar 2.999. sedangkan $t_{\text {tabel }}$ sebesar 1,683. Berdasarkan kaidah pengambilan keputusan, karena $t_{\text {hitung }}>t_{\text {tabel }}$ maka maka $\mathrm{H}_{0}$ ditolak dan $\mathrm{H}_{\mathrm{a}}$ diterima yang berarti terdapat perbedaan hasil belajar menggunakan metode TGT dan TAI pada materi ajar tata nama senyawa kelas X SMA Negeri 12 Banjarmasin dimana kelas TAI memiliki nilai rata-rata posttest yang lebih tinggi daripada kelas TGT. Hasil penelitian ini sesuai dengan temuan dalam penelitian oleh Sarwendah, Martini, dan Utami (2013) yang telah dijelaskan sebelumnya bahwa nilai posttest kelas yang menggunakan metode TAI lebih tinggi dibandingkan dengan kelas yang menggunakan TGT. Sehingga, dapat disimpulkan bahwa metode TAI lebih cocok diterapkan di kelas X SMA Negeri 12 Banjarmasin dibandingkan metode TGT. Hal ini dimungkinkan karena pada kelas TAI lebih banyak waktu yang digunakan untuk belajar bersama memahami materi dan memecahkan soal, sedangkan pada kelas TGT waktu lebih banyak tersita untuk melakukan turnamen. Namun, hal ini bertentangan dengan beberapa hasil penelitian terdahulu yang menyatakan bahwa model TGT efektif untuk meningkatkan hasil belajar (Pawestri, 2009), (Yasa, Sunarya, \& Santyadiputra, 2015). Kedua penelitian tersebut membuktikan bahwa model pembelajaran TGT mampu meningkatkan hasil belajar siswa; yang berarti jika dihubungkan dengan hasil penelitian ini, maka kedua model pembelajaran TGT dan TAI memiliki pengaruh positif terhadap hasil belajar, namun terdapat perbedaan antara kedua model pembelajaran tersebut dimana kelas TAI memiliki peningkatan hasil belajar yang lebih besar. Hal ini tidak membuktikan bahwa model TAI lebih baik dibandingkan model TGT, namun dalam kasus penggunaan kedua model untuk topik pembahasan tata nama senyawa model pembelajaran TAI lebih cocok digunakan untuk meningkatkan hasil belajar siswa.

\section{SIMPULAN}

Berdasarkan hasil dan analisa peneliti diperoleh kesimpulan yaitu terdapat perbedaan hasil belajar siswa yang diajar menggunakan metode TGT (Teams Games 
Tournament) dengan siswa yang diajar menggunakan TAI (Team Assisted Individualization) pada materi ajar tata nama senyawa kelas X SMA Negeri 12 Banjarmasin, rata-rata nilai hasil belajar siswa yang diajar menggunakan metode TAI (Team Assisted Individualization) lebih tinggi daripada rata-rata nilai hasil belajar siswa yang diajar menggunakan metode TGT (Teams Games Tournament), pembelajaran dengan metode TAI lebih efektif daripada metode TGT dalam mengajarkan materi tata nama senyawa di kelas X SMA Negeri 12 Banjarmasin.

\section{DAFTAR RUJUKAN}

Arikunto, S. (2006). Prosedur Penelitian Suatu Pendekatan Praktik. Jakarta: PT Rineka Cipta.

Arjanggi, R., \& Suprihatin, T. (2010). Metode Pembelajaran Tutor Teman Sebaya Meningkatkan Hasil belajar Berdasar Regulasi-Diri. Makara, Sosial Humaniora, 14(2), 91-97.

Hariyati, E., Mardiyana, \& Usodo, B. (2013). Efektivitas Model Pembelajaran Kooperatif Tipe Team Assisted Individualization (Tai)Dan Problem Based Learning (Pbl) Pada Prestasi Belajar Matematika Ditinjau Dari Multiple Intelligences Siswa SMP Kabupaten Lampung Timur Tahun Pelajaran 2012/2013. Jurnal Elektronik Pembelajaran Matematika, 1(7), 721-731.

Irianto, A. (2009). Statistik Konsep Dasar dan Aplikasinya. Jakarta: Kencana.

Margono. (2014). Metodologi Penelitian Pendidikan. Jakarta: Rineka Cipta.

Nurdyansyah, \& Toyiba, F. (2018). Pengaruh Strategi Pembelajaran Aktif Terhadap Hasil Belajar pada Madrasah Ibtidaiyah. Sidoarjo: Program Studi Pendidikan Guru madrasah Ibtidaiyah Fakultas Agama Islam Universitas Muhammadiyah sidoarjo.

Pawestri, D. C. (2009). Penerapan Model Pembelajaran Kooperatif Teams Games Tournament (Tgt) Pada Mata Pelajaran Ekonomi Sebagai Upaya Meningkatkan Hasil Belajar Siswa Kelas X SMA Muhammadiyah 3 Surakartatahun Pelajaran 2008/2009. Surakarta: Universitas Sebelas Maret.

Rosida, P., \& Suprihatin, T. (2011). Pengaruh Pembelajaran Aktif dalam Meningkatkan Prestasi Belajar Fisika pada Siswa Kelas 2 SMU. Proyeksi, 6(2), 89-102.

Sarwendah, Martini, K. S., \& Utami, B. (2013). Studi Komparasi Pembelajaran Kimia Menggunakan Model Pembelajaran Kooperatif Metode Teams Games Tournaments (TGT) dan Team Assisted Individualization (TAI) pada Materi Pokok Sistem Koloid Kelas XI IPA SMA Negeri 2 Sukoharjo Tahun Pelajaran 2011/2012. Jurnal Pendidikan Kimia, 2(1), 42-47.

Sugiyono. (2013). Metodologi Penelitian Kuantitatif, Kualitatif, dan $R \& D$. Bandung: PT Alfabeta.

Suhadi, E., Mujahidin, E., Bahrudin, E., \& Tafsir, A. (2014). Pengembangan Motivasi dan Kompetensi Guru Dalam Peningkatan Mutu Pembelajaran di Madrasah. Ta'dibuna: Jurnal Pendidikan Islam, 3(1), 43-61.

Sujarweni, W., \& Endrayanto, P. (2012). Statistika untuk Penelitian. Yogyakarta: Graha Ilmu.

Warsono, H., \& Hariyanto, M. (2012). Pembelajaran Aktif Teori dan Asesmen. Bandung: PT Remaja Rosdakarya. 
Dalton : Jurnal Pendidikan Kimia dan Ilmu Kimia, Volume 2 Nomor 1, Mei 2019

Yasa, K. S., Sunarya, M. G., \& Santyadiputra, G. S. (2015). Pengaruh Model Pembelajaran Teams Games Tournaments (Tgt) Berbantuan Talking Stick (Ts) Berlandaskan Local Genius Tri Pramana Terhadap Hasil Belajar Simulasi Digital Siswa Kelas X Jurusan Perhotelan Di SMK Negeri 2 Singaraja. KARMAPATI, $4(4), 1-7$. 